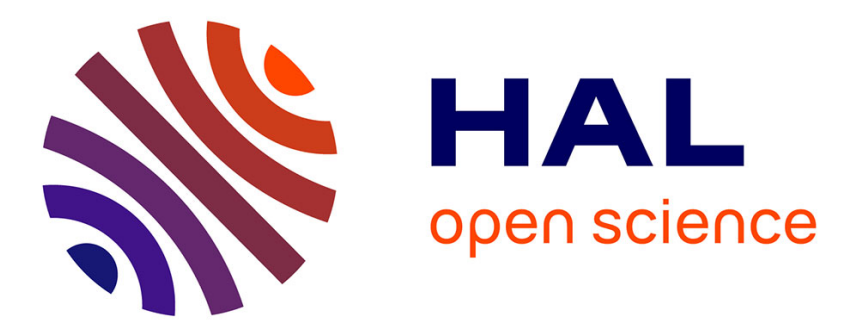

\title{
Reduced form wage equations in the credible bargaining model
}

\author{
Vincent Boitier, Antoine Lepetit
}

\section{To cite this version:}

Vincent Boitier, Antoine Lepetit. Reduced form wage equations in the credible bargaining model. Labour Economics, 2018, 50, pp.92-96. 10.1016/j.labeco.2016.04.003 . hal-01088831

\section{HAL Id: hal-01088831 \\ https://hal.science/hal-01088831}

Submitted on 28 Nov 2014

HAL is a multi-disciplinary open access archive for the deposit and dissemination of scientific research documents, whether they are published or not. The documents may come from teaching and research institutions in France or abroad, or from public or private research centers.
L'archive ouverte pluridisciplinaire HAL, est destinée au dépôt et à la diffusion de documents scientifiques de niveau recherche, publiés ou non, émanant des établissements d'enseignement et de recherche français ou étrangers, des laboratoires publics ou privés. 


\title{
Reduced form wage equations in the credible bargaining model*
}

\author{
Vincent Boitier ${ }^{\dagger} \quad$ Antoine Lepetit ${ }^{\ddagger}$
}

\begin{abstract}
We derive an analytical solution for the wage from an alternating-offer wage bargaining game à la Hall and Milgrom (2008) under a plausible parameter restriction. This solution is simple, micro-founded and permits a transparent analysis of the driving forces of wages. We argue that it can be used in a wide range of economic models incorporating the search and matching theory of unemployment to simplify the analysis and obtain more easily interpretable results.
\end{abstract}

JEL Codes : E2, J3, J6.

Keywords: search and matching models; credible bargaining; wage rigidity.

\footnotetext{
${ }^{*}$ We would like to thank Francesco Furlanetto for his very useful comments.

${ }^{\dagger}$ Paris School of Economics and University Paris 1 Panthéon-Sorbonne, vincent.boitier@univ-paris1.fr.

${ }_{\ddagger}^{\ddagger}$ Paris School of Economics and University Paris 1 Panthéon-Sorbonne, antoine.lepetit@univ-paris1.fr.
} 


\section{Introduction}

The search and matching framework has become an essential tool for the analysis of unemployment and the labor market. Because search frictions give rise to a surplus that has to be shared between firms and workers, the private efficiency of employment relationships is consistent with a broad range of wage setting mechanisms. Hall and Milgrom (2008) have proposed an increasingly popular alternative to the standard Nash model of wage determination. It offers the advantage of addressing the so-called Shimer puzzle, namely the inability of the canonical search and matching model to replicate the volatility of labor market variables observed in the data. It does so by providing a micro-foundation for wage rigidity. These authors argue that the threat points of both employers and job seekers are to delay bargaining rather than terminate it. This tends to insulate wages from outside conditions in the labor market and make them endogenously rigid.

In the baseline version of this model, an analytical expression for real wages cannot be derived. As a consequence, introducing it in an otherwise standard search and matching frictions framework can substantially complexify the analysis. We show that is it possible to circumvent this problem and derive a reduced form wage equation from an alternating-offer wage bargaining game à la Hall and Milgrom (2008) by imposing a plausible parameter restriction. More precisely, we impose that the probability of breakdown in bargaining is equal to the separation rate. In our specification, wages are partially connected to outside labor market conditions through the difference between the current and the expected values of unemployment. On the one hand, an increase in the current value of unemployment leads to an increase in the threat point of workers in bargaining and puts upward pressure on wages. On the other hand, an increase in the future value of unemployment leads workers to value more current employment and temper their wage claims. We provide a detailed account of how our simple wage equation could be used in a wide range of models incorporating the search and matching theory of unemployment to simplify the analysis.

The note is structured as follows. Section 2 develops a standard search and matching model of the labor market. Section 3 presents the alternating-offer bargaining game and derives the analytical solution for the wage. Section 4 analyzes the driving forces of wages and discusses how our simple expression could be used in the literature. Section 5 concludes.

\section{Model}

Consider a discrete time version of the search and matching model of Pissarides (2000). Firms and workers must match in the labor market in order to become productive. Matches 
are formed according to a constant returns to scale production function $m_{t}=\mu u_{t}^{\alpha} v_{t}^{1-\alpha}$ where $u$ is the number of job seekers, $v$ the number of open vacancies and $0<\alpha<1$. Unemployed workers find a job with probability $f(\theta)=\frac{m_{t}}{u_{t}}$ and vacancies are filled at a rate $q(\theta)=\frac{m_{t}}{v_{t}}$ where $\theta=\frac{v}{u}$ is a measure of labor market tightness. At the beginning of each period, a fraction $s$ of existing employment relationships is exogenously destroyed. Matches formed in one period become operational in the next period. The law of motion of employment $n_{t}$ is accordingly given by:

$$
n_{t}=(1-s) n_{t-1}+m_{t-1}
$$

Workers are risk neutral and do not have access to financial markets. They can be either employed or unemployed. The values $W_{t}$ and $U_{t}$ associated with those two states are given by:

$$
\begin{gathered}
W_{t}=w_{t}+e^{-r}\left[(1-s) E_{t} W_{t+1}+s E_{t} U_{t+1}\right] \\
U_{t}=b+e^{-r}\left[f\left(\theta_{t}\right) E_{t} W_{t+1}+\left(1-f\left(\theta_{t}\right)\right) E_{t} U_{t+1}\right]
\end{gathered}
$$

where $r$ is the discount rate and $\beta=\frac{1}{1+r} \approx e^{-r}$ is the discount factor. When employed, workers receive a wage $w_{t}$ and can expect to remain employed with probability $1-s$. When unemployed, workers receive the flow value of unemployment $b$ and can expect to find a job with probability $f\left(\theta_{t}\right)$. Firms operate with a constant returns to scale production function $y_{t}=z_{t} n_{t}$ where $z_{t}$, the state of technology, evolves according to an $\operatorname{AR}(1)$ process. They must pay a cost $c$ to post a vacancy. The firm's values of a filled and an unfilled vacancy $J_{t}$ and $V_{t}$ are thus given by:

$$
\begin{gathered}
J_{t}=z_{t}-w_{t}+e^{-r}\left[(1-s) E_{t} J_{t+1}+s E_{t} V_{t+1}\right] \\
V_{t}=-c+e^{-r}\left[q\left(\theta_{t}\right) E_{t} J_{t+1}+\left(1-q\left(\theta_{t}\right)\right) E_{t} V_{t+1}\right]
\end{gathered}
$$

Free entry in the posting of vacancies implies $V_{t}=0$. Therefore the job creation equation is:

$$
\frac{c}{q\left(\theta_{t}\right)}=e^{-r} E_{t} J_{t+1}
$$

\section{The alternating-offer wage bargain}

Wages are determined according to a sequential bargaining game à la Binmore et al. (1986). Hall and Milgrom (2005) note that "many rounds of bargaining can occur within each period of search and employment". In line with this intuition, we assume that each period is divided into sub-periods during which bargaining takes place. The time interval separating one sub-period from another is $\tau$. Firms begin the game by making an offer $w$ to the worker. If the offer is accepted, the game ends. If the offer is rejected, the game goes on to 
the next sub-period when the worker makes a counter-offer $w^{\prime}$ to the firm. During this time interval, the firm incurs a flow cost $\gamma \tau$ while the worker receives flow benefits $b \tau$. Moreover, before the worker makes his counter-offer, negotiations can breakdown with hazard $\delta$. In this case, the worker gets $U$ whereas the firm gets nothing. Otherwise, the game continues to the next sub-period. In this setting, it is optimal for each party to always make a just acceptable offer to the other side. Thus, the following equations govern the game: ${ }^{1}$

$$
\begin{gathered}
W_{t}^{w}=b \tau+e^{-r \tau}\left[\left(1-e^{-\delta \tau}\right) U_{t}+e^{-\delta \tau} W_{t}^{w^{\prime}}\right] \\
J_{t}^{w^{\prime}}=-\gamma \tau+e^{-(r+\delta) \tau} J_{t}^{w}
\end{gathered}
$$

Solving equations (7) and (8) for $w$ (or equivalently for $w^{\prime}$ ) and letting $\tau \rightarrow 0$, we obtain the following sharing rule: ${ }^{2}$

$$
W_{t}-\frac{b}{r+\delta}-\frac{\delta U_{t}}{r+\delta}=J_{t}+\frac{\gamma}{r+\delta}
$$

This equation is similar to equation (17) in Hall and Milgrom (2005). Under the assumption that the probability of breakdown during bargaining $\delta$ is equal to the separation rate $s$, and after using this sharing rule along with equations (2) and (4), we obtain:

$$
w_{t}=\frac{1}{2}\left[z_{t}+\beta(b+\gamma)+\frac{\delta}{r+\delta}\left(U_{t}-E_{t} U_{t+1}\right)\right]
$$

This simple wage equation is our main result. Hall and Milgrom (2008) set $\delta$ in order to match the volatility of the unemployment rate. The employer's cost of delay, $\gamma$, plays a similar role than $\delta$ in that it influences directly the volatility of unemployment. When $\gamma$ is high, firms' surplus is small and changes significantly in percentage terms in response to shocks. As a result, stochastic variations in technology lead to important movements in job creation and unemployment. The converse reasoning holds when $\gamma$ is low. Since knowledge about both the values of $\gamma$ and $\delta$ is limited, we believe it is equivalent to fix one to a particular value and let the other adjust to match the volatility of the unemployment rate. Unlike Hall and Milgrom (2008), we choose $\delta=s$ and propose to fix $\gamma$ to match the volatility of the unemployment rate. This calibration strategy has the advantage of enabling us to derive a simple analytical expression for the wage. It also represents an intermediate choice in the literature. Hall and Milgrom (2008) obtain a probability of breakdown that is five times as high as the separation rate whereas Christiano et al. (2013) estimate a medium-scale dynamic stochastic general equilibrium model encompassing an alternating-offer model of wage-setting on U.S. data and find a value of the probability of breakdown that is lower than the separation rate.

\footnotetext{
${ }^{1}$ We follow strictly Hall and Milgrom (2005) when defining the equations governing the game.

${ }^{2}$ See Appendix A.
} 


\section{The wage equation: potential use}

\subsection{The steady-state equation}

In steady-state, equation (10) collapses to

$$
w=\frac{1}{2}[z+\beta(b+\gamma)]
$$

The complete isolation of the wage from labor market conditions in that case has a simple intuitive explanation. On one hand, an increase in the value of unemployment $U$ leads to an increase in the threat point of workers in bargaining and puts an upward pressure on wages. On the other hand, an increase in $U$ leads to an increase in the value of employment $W$ for the worker. As workers value more employment, they accept lower wages. When $\delta=s$, those two effects cancel out. Mortensen and Nágypál (2007) obtain a similar expression within the context of an alternating-offer game with no probability of breakdown during bargaining by imposing that the separation rate $s$ is equal to zero. We show that it is possible to find a simple analytical solution for the wage in a more realistic setup. We allow for a positive probability of breakdown during bargaining and do not impose that the separation rate is equal to zero. A similar result was also uncovered by Ljungqvist and Sargent (2014) in recent and independent work.

We believe equation (11) could be of great use in articles incorporating a steady-state labor market frictions model. In that type of framework, when wages are determined according to a generalized Nash bargaining game, the job creation equation becomes nonlinear in labor market tightness. One needs to solve for it numerically and this rules out the possibility of obtaining analytical results. This problem does not arise when using our simple wage solution. Because wages do not depend on labor market tightness in equation (11), analytical expressions for all variables in the model can readily be obtained.

\subsection{The dynamic case}

In the more general dynamic case, the wage is not completely isolated from labor market conditions as $U_{t}$ and $E_{t} U_{t+1}$ may differ (see equation (10)). Consider that the value of unemployment increases both today and in the future in response to a positive technology shock. In the event that $U_{t}-E_{t} U_{t+1}>0$, the wage moderating effect of an increase in the value of employment will be more than offset by the effect arising from the stronger bargaining position of the worker and the improvement in labor market conditions will put upward pressure on wages. When $U_{t}-E_{t} U_{t+1}<0$, the inverse reasoning holds and the improvement in labor market conditions depresses wages. 
In recent years, a large literature has incorporated the search and matching theory of unemployment in dynamic stochastic general equilibrium models (DSGE) to study, among others things, the impact of fiscal and monetary policies on the labor market and the joint dynamics of inflation and unemployment. As pointed out in the introduction, when wages are Nash-bargained, these models embedding a search structure are unable to account for the volatility of labor market variables observed in U.S. data. Several fixes, including wage rigidity, have been proposed to solve this problem. Because of its micro-founded nature and its ability to generate wage rigidity endogenously, the credible bargaining model of wage-setting is becoming increasingly popular in the literature. However, in the standard setup proposed by Hall and Milgrom (2008), an analytical expression for wages cannot be derived. This has an undesirable consequence; when this model of wage-setting is used, it is generally impossible to find analytical and easily interpretable results. Some authors have circumvented this problem by using simple ad-hoc wage equations which preserve the main feature of the setup, that is, the partial isolation of wages from labor market conditions. In Jung and Kuester (2011), wages are a weighted average of the technological level and the fixed outside option of workers during bargaining and are fully insulated from labor market conditions. We nest their specification when $\delta=s=0$ and $\beta=1$. Hall (2014) justifies the introduction of a parameter that controls the role of labor market tightness in the Nash-bargained wage equation by invoking the logic of the alternating-offer bargaining game. Although his equation cannot be formally derived from a bargaining game, a low value for this parameter corresponds to a low value for the probability of breakdown in the credible bargaining model.

We believe our wage solution could permit a wider use of the credible bargaining framework in these dynamic models. In equation (10), the expression is both micro-founded and simple to use, and the driving forces of wages are transparent. We argue that since knowledge about the values of the probability of breakdown in bargaining $\delta$ and the employer's cost of delay $\gamma$ is limited, fixing one of these parameters and letting the other vary to match key labor market moments is equivalent. We fix $\delta=s$ and let $\gamma$ vary to obtain the advantage of the analytical solution. This strategy has an unanticipated side benefit. In the appendix, we show that when calibrating the model to standard values and matching the standard deviation of the component of unemployment driven by productivity as in Hall and Milgrom (2008), we obtain a short-run elasticity of wages with respect to labor productivity of about 0.8 , in line with empirical estimates reported in Haefke et al. (2013). ${ }^{3}$ This is because the $U_{t}-E_{t} U_{t+1}$ term reacts in a pro-cyclical way to technology shocks. Thus, on top of its simplicity, our wage equation is consistent with important labor market facts.

\footnotetext{
${ }^{3}$ See Appendix B.
} 


\section{Conclusion}

We derive a reduced form wage equation from an alternating-offer wage bargaining game la Hall and Milgrom (2008) under a plausible parameter restriction. Our simple equation connects wages to outside labor market conditions through the difference between the current and the future values of unemployment. It can easily be used in studies wishing to obtain analytical results, permits a transparent analysis of the driving forces of wages, and is consistent with key labor market facts 


\section{References}

[1] Binmore, K., Rubinstein, A., Wolinsky, A., 1986. The Nash bargaining solution in economic modelling. RAND J. of Econ. 17, 176-188.

[2] Christiano, L., Eichenbaum, M., Trabandt M., 2013. Unemployment and business cycles. Mimeo.

[3] Hall, R., Milgrom, P., 2008. The limited influence of unemployment on the wage bargain. Amer. Econ. Rev. 98, 1653-1674.

[4] Haefke, C., Sonntagd, S., van Rens, T., 2013. Wage rigidity and job creation. J. of Mon. Econ. 60, 887899.

[5] Hall, R., Milgrom, P., 2005. The limited influence of unemployment on the wage bargain. Working Paper, Stanford University.

[6] Jung, P., Kuester K., 2011. The (un)importance of unemployment fluctuations for the welfare cost of business cycles. J. of Econ. Dynam. and Control 35, 1744-1768.

[7] Ljungqvist, L., Sargent, T., 2014. The fundamental surplus in matching models. Mimeo.

[8] Mortensen, D., Nágypál, E., 2007. More on unemployment and vacancy fluctuations. Rev. of Econ. Dynam. 10, 327-347.

[9] Petrongolo, B., Pissarides, C., 2001. Looking into the black box: a survey of the matching function. J. of Econ. Literature 39, 390-431.

[10] Pissarides, C., 2000. Equilibrium unemployment theory. MIT Press, Cambridge.

[11] Shimer, R., 2005. The cyclical behavior of equilibrium unemployment and vacancies. Amer. Econ. Rev. 95, 25-49. 


\section{A Derivations of (9), (10) and (11)}

The subgame perfect equilibrium of the sequential game satisfies:

$$
W_{t}^{w}=b \tau+e^{-r \tau}\left[\left(1-e^{-\delta \tau}\right) U_{t}+e^{-\delta \tau} W_{t}^{w^{\prime}}\right]
$$

and

$$
J_{t}^{w^{\prime}}=-\gamma \tau+e^{-(r+\delta) \tau} J_{t}^{w}
$$

with

$$
\begin{gathered}
W_{t}^{w}=w_{t}+e^{-r}\left[(1-s) E_{t} W_{t+1}+s E_{t} U_{t+1}\right] \\
W_{t}^{w^{\prime}}=w_{t}^{\prime}+e^{-r}\left[(1-s) E_{t} W_{t+1}+s E_{t} U_{t+1}\right] \\
J_{t}^{w^{\prime}}=z_{t}-w_{t}^{\prime}+e^{-r}(1-s) E_{t} J_{t+1} \\
J_{t}^{w}=z_{t}-w_{t}+e^{-r}(1-s) E_{t} J_{t+1}
\end{gathered}
$$

because $V_{t}=V_{t+1}=0$. Plugging (14) and (15) in (12) leads to:

$$
w_{t}+\left[1-e^{-(r+\delta) \tau}\right] e^{-r}\left[(1-s) E_{t} W_{t+1}+s E_{t} U_{t+1}\right]=b \tau+e^{-r \tau}\left(1-e^{-\delta \tau}\right) U_{t}+e^{-(r+\delta) \tau} w_{t}^{\prime}
$$

Likewise, integrating equations (16) and (17) in equation (13) gives:

$$
w_{t}^{\prime}=\gamma \tau+\left[1-e^{-(r+\delta) \tau}\right] z_{t}+\left[1-e^{-(r+\delta) \tau}\right] e^{-r}(1-s) E_{t} J_{t+1}+e^{-(r+\delta) \tau} w_{t}
$$

Combining the two equations above and letting $\tau \rightarrow 0$, we find:

$$
2 w_{t}+e^{-r}\left[(1-s) E_{t} W_{t+1}+s E_{t} U_{t+1}\right]=\frac{b+\gamma}{r+\delta}+\frac{\delta U_{t}}{r+\delta}+z_{t}+e^{-r}(1-s) E_{t} J_{t+1}
$$

because, when $\tau \rightarrow 0, e^{-a \tau}=1-a \tau$ with $a$ a constant. Noting that $W_{t}^{w}=W_{t}$ and $J_{t}^{w}=J_{t}$, we get:

$$
W_{t}-\frac{b}{r+\delta}-\frac{\delta U_{t}}{r+\delta}=J_{t}+\frac{\gamma}{r+\delta}
$$

Introducing the expressions of $W_{t}$ and $J_{t}$ in (18) leads to:

$$
2 w_{t}+\beta(1-s)\left[E_{t} W_{t+1}-E_{t} J_{t+1}\right]=z_{t}+\frac{b+\gamma}{r+\delta}+\frac{\delta U_{t}}{r+\delta}-\beta s E_{t} U_{t+1}
$$

since $e^{-r} \approx \beta=\frac{1}{1+r}$. Using the sharing rule, we obtain:

$$
E_{t} W_{t+1}-E_{t} J_{t+1}=\frac{\delta E_{t} U_{t+1}}{r+\delta}+\frac{b+\gamma}{r+\delta}
$$

Using the above equation and (18), we have:

$$
2 w_{t}=z_{t}+\frac{[1-\beta(1-s)](b+\gamma)}{(r+\delta)}-\frac{\delta U_{t}}{r+\delta}-\left[\beta s+\frac{\beta(1-s) \delta}{r+\delta}\right] E_{t} U_{t+1}
$$


that is:

$$
w_{t}=\frac{z_{t}}{2}+\frac{(r+s)(b+\gamma)}{2(r+\delta)(1+r)}-\frac{\delta U_{t}}{2(r+\delta)}-\frac{(s r+\delta) E_{t} U_{t+1}}{2(r+\delta)(1+r)}
$$

If $\delta=s$ then:

$$
w_{t}=\frac{1}{2}\left[z+\beta(b+\gamma)+\frac{\delta\left(U_{t}-E_{t} U_{t+1}\right)}{r+\delta}\right]
$$

Last, at steady state, $E_{t} U_{t+1}=U_{t}=U$ implying that:

$$
w=\frac{1}{2}[z+\beta(b+\gamma)]
$$

\section{B Calibration exercise}

We calibrate the model in a conventional manner. We take one period to be a month. The discount factor is set to $\beta=0.99$, which yields an interest rate of $4 \%$ annually. The elasticity of matches with respect to unemployment is assumed to be $\alpha=0.5$, in line with estimates in Petrongolo and Pissarides (2000). Following Shimer (2005), the separation rate is set to 0.034 and the steady-state job finding rate to 0.45 . Given a steady-state labor market tightness of 0.7 , matching efficiency $\mu$ is then determined through steady-state relationships. We set the flow value of unemployment to 0.71 and choose the employer's cost of delay $\gamma$ to match a standard deviation of the component of unemployment driven by productivity of 0.68 percentage points, following Hall and Milgrom (2008). Vacancy posting costs $\mathrm{c}$ are then determined through steady-state relationships. Finally, we use standard values for the autoregressive parameter and the standard deviation of the technology shock, $\rho=0.95^{1 / 3}$ and $\sigma_{z}=0.0075$. Figure 1 presents the impulse response functions of selected
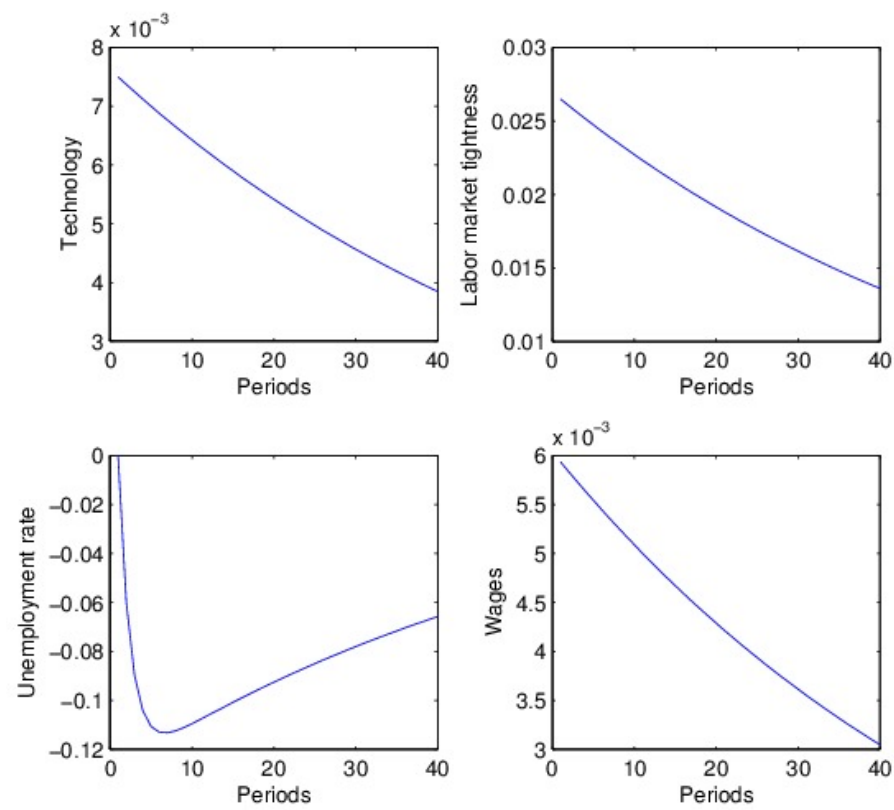
variables to a positive technology shock. The short-run elasticity of wages with respect to labor productivity is computed in each period by using the following formula $\varepsilon_{t}^{w, z}=\frac{\frac{w_{t}-w}{w}}{\frac{w}{z_{t}-z}}$ with $w$ and $z$ being the steady-state values of wages and technology. It is approximately equal to 0.84 from period 1 to period 30 . 